\title{
Robustness of Air Transportation as Complex Networks: Systematic Review of 15 Years of Research and Outlook into the Future
}

\author{
Xiaoqian Sun $(1)$ and Sebastian Wandelt *(1)
}

Citation: Sun, X.; Wandelt, S.

Robustness of Air Transportation as

Complex Networks: Systematic

Review of 15 Years of Research and

Outlook into the Future. Sustainability

2021, 13, 6446. https://doi.org/

$10.3390 /$ su13116446

Academic Editors: Jin-Woo Park and Armando Cartenì

Received: 19 March 2021

Accepted: 2 June 2021

Published: 6 June 2021

Publisher's Note: MDPI stays neutral with regard to jurisdictional claims in published maps and institutional affiliations.

Copyright: (C) 2021 by the authors. Licensee MDPI, Basel, Switzerland. This article is an open access article distributed under the terms and conditions of the Creative Commons Attribution (CC BY) license (https:// creativecommons.org/licenses/by/ $4.0 /)$
School of Electronic and Information Engineering, Beihang University, Beijing 100191, China; sunxq@buaa.edu.cn

* Correspondence: wandelt@informatik.hu-berlin.de

\begin{abstract}
Air transportation systems are an important part of the critical infrastructure in our connected world. Accordingly, a better understanding and improvements in the resilience of the overall air transportation system are essential to the well-functioning of our society and overall sustainability of human beings. In the literature, network science is increasingly used to better understand the resilience dynamics of air transportation. Given the wide application of tools for network science and the importance of designing resilient air transportation systems, a rich body of studies has emerged in recent years. This review paper synthesizes the related literature that has been published throughout the last 15 years regarding the robustness of air transportation systems. The contributions of this work consist of two major elements. The first part provides a comprehensive discussion and cross-comparison of the reported results. We cover several major topics, including node importance identification, failure versus attack profiles, recovery and improvement techniques, and networks of networks approaches. The second part of this paper complements the review of aggregated findings by elaborating on a future agenda for robust air transportation research. Our survey-style overview hopefully contributes toward a better understanding of the state of the art in this research area, and, in turn, to the improvement of future air transportation resilience and sustainability.
\end{abstract}

Keywords: air transportation; airport network; robustness; resilience; review

\section{Introduction}

Globalization, increased wealth, and advanced accessibility have led to tremendous increases in air transport operations throughout recent decades, with regular yearly passenger increases of 5-10\%. The growth, together with the extraordinary requirements of efficiency in air transportation and ongoing competition between airlines and high-speed rail [1], comes with an inevitable increase in operational complexity and risks for disturbances. Such disturbances include, but are not limited to, extreme weather, geological abnormalities, terrorist attacks, and congestion-based cascades.

Analyzing the impact of such disruptions and the resilience of air transportation is not simply an academic exercise but has huge impacts on our society and the overall environmental and economical sustainability of human beings; see [2] for a recent survey on how the concept resilience should be understood in the context of sustainability. From the sustainability perspective, disruptions to air transportation may incur huge economic losses. Examples for recent large-scale disruptions to transportation systems include the European air traffic outage caused by the Icelandic Eyjafjallajökull volcano [3], power outages of the major hub airport in Atlanta [4], and the impact of COVID-19 on global air transportation [5]. In addition to the economic losses, the impact on human mobility and social behavior are devastating [6].

To better understand resilience, it is critical to identify the complexity and hidden dynamic patterns of air transportation systems. Network science, as developed in the last 
two decades, provides excellent tools for understanding the structure and dynamics of the system [7-9]. In such network models, nodes are usually individual airports or air navigation route points, and links are connections between the elements of interest.

Figure 1 presents an example of the Chinese airport network from 2019, where the nodes are airports and links are direct flights. The weight of the links (visualized by their thickness) corresponds to the number of flights per day (as of 1 August 2019). The top 20 airports according to the total number of passengers are highlighted by their IATA code, with the green circle growing with the total number of passengers. It can be seen that some airports in the network are better connected than others-in other words, these airports are more central in the network regarding direct connectivity.

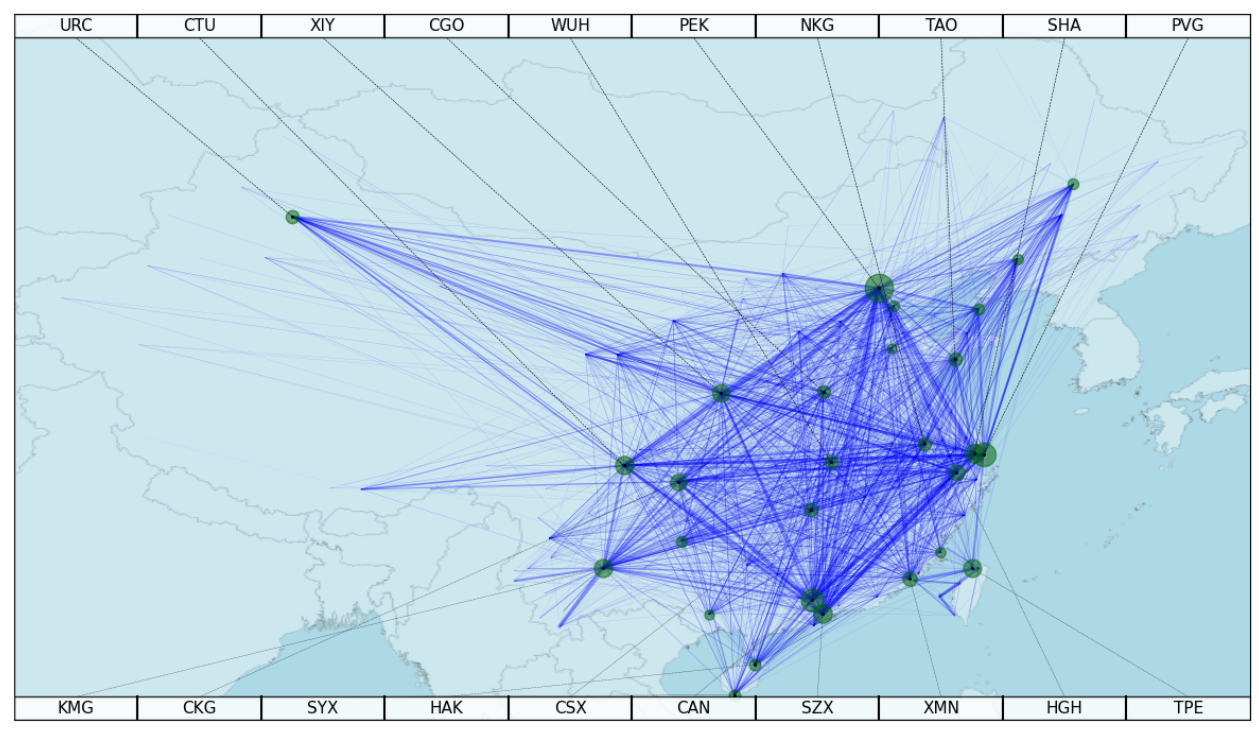

Figure 1. Chinese air transportation network on 1 August 2019.

A pioneering study [10] in the area of air transportation analysis discussed the worldwide air transportation systems using complex network techniques and discovered several anomalous centrality relationships (based on the number of direct connections versus the shortest path-centrality) and also the roles of cities in the network. For the last 15 years, based on this initial study, many researchers have applied similar techniques to analyze the criticality of system components in the worldwide air transportation system and its subsystems.

The goal of this paper is to provide a review of the state-of-the-art in complex networks for assessing the robustness of air transportation systems. In total, a collection of more than 100 papers were identified in the literature, following keyword-based searches on academic search engines (Google Scholar and Microsoft Academic) together with archival webpages of large academic publishers. These papers, at their heart, aim to understand and improve the robustness of the overall air transportation system, yet, often have unique purposes.

For the sake of this literature review, we identify several recurring streams of topics, including node importance identification, failure versus attack profiles, recovery and improvement techniques, and networks of networks approaches. For each category, we report the overall problem, together with a brief summary of each paper. Finally, this study continues with the derivation of seven directions for future work. We elucidate how complex network techniques can help to better understand the operational dynamics underlying the air transportation system.

The remainder of this study is structured as follows. Section 2 is the heart of the literature review, providing an overview on recent advances, grouped into categories. Section 4 discusses the findings from the literature and elaborates on how these findings lead to directions for future work. 


\section{Literature Review}

A wide range of studies have reported results on various application domains, taking different perspectives on network robustness. Based on the collected literature, we have sorted all papers into eight categories reported in individual sections as follows. Section 2.1 reports on the phenomenon that random failures in the air transportation system are usually less harmful than targeted attacks; an effect that has been shown on many subsystems. Section 2.2 focuses on the identification of important nodes in the network, which can be based on various techniques, including node centralities and active dismantling approaches. Section 2.3 discusses the complementary problems of link importance identification, which received comparatively less attention in the literature. Section 2.4 discusses the literature on the recovery process and ways to improve the robustness of air transportation networks.

Section 2.5 provides a succinct discussion of studies on the evolution of system properties throughout the process of dismantling. Section 2.6 takes the perspective of systems-of-systems, by reporting on studies that treat air transportation as a network of networks. Section 2.7 gives an overview on the robustness measures presented in the literature, including giant component, percolation theory, shock propagation, and adaptive capacity. Section 2.8 reviews other studies that do not directly contribute to the topics in one of the earlier sections. It should be noted that some studies fit multiple sections. We have usually reported studies in the section that we considered most relevant, and only reported studies multiple times in cases where it is instructive for understanding the state of the art. Since the vast majority of other studies on airport network robustness are based on the size of the giant component, the remainder of this survey refers the giant component as the robustness measure, unless mentioned otherwise.

\subsection{Targeted Attacks Are More Harmful Than Random Failures}

A wide range of studies in the literature analyze the different impacts of targeted attacks versus random failures. A random failure is the outage (or removal) of nodes in random-uniformly chosen order, i.e., each node has the same initial probability to fail. Random failure traces are not unique, and in order to generate a representative set of traces, one needs to run a considerable number of simulations, especially for larger networks.

A targeted attack, on the other hand, is controlled by an informed process, which selects nodes based on a given importance or centrality measure, where more important nodes are attacked first. From a sustainability point of view, failures cannot be prevented; but it is necessary to understand the degree of damage that can be caused by these unavoidable outages, especially in presence of a cascade, which will lead to huge economic and social losses. A better understanding of targeted attacks helps our society to increase the protection of critical infrastructure for selected components. Accordingly, society should carefully distinguish the roles of airports under failures and intentional attacks.

Figure 2 shows the effectual difference between random and targeted attacks. Here, four widely-used network metrics are used for comparison (see Section 2.2 for more details). It can be seen for the figure that the size of the network's giant component is much more resilient to random failures (left) than to targeted attack (right). Many studies report this insight on air transportation (sub-)systems. The studies shown in Table 1 have a major focus on reporting this observation on different network types and subsets. 
Table 1. Random failures versus targeted attacks.

\begin{tabular}{ll}
\hline Study & Major Finding \\
\hline Chi et al., 2004 [11] & $\begin{array}{l}\text { Studied the US airport network and revealed a high degree of error tolerance and an extreme } \\
\text { vulnerability to targeted attacks. }\end{array}$ \\
\hline Hossain et al., 2013 [12] & $\begin{array}{l}\text { Measured the robustness of the Australian airline network (131 nodes and 596 links). They found } \\
\text { that the network was robust against random failures but vulnerable against targeted attacks. }\end{array}$ \\
\hline Bing, 2014 [13] & $\begin{array}{l}\text { Analyzed the airport network of China Southern Airlines (187 nodes and 1245 links). Nodes were } \\
\text { ranked according to degree and betweenness, in descending order, and the robustness of the network } \\
\text { was measured in terms of four different indicators (vertex betweenness, flow betweenness, closeness, } \\
\text { and degree). The authors also performed experiments on weighted networks. Once two highest- } \\
\text { degree airports were removed from the network, the north-south interaction was greatly affected; } \\
\text { but when the two highest-betweenness were removed, the network connectivity between west and } \\
\text { east was mostly affected. }\end{array}$ \\
\hline
\end{tabular}

Li et al., 2015 [14] Proposed two spatial vulnerability indexes, distinguishing absolute and relative vulnerability. These indexes were evaluated in the Chinese airport network (173 nodes).

Agrawal et al., 2015 [15] Studied the impact of short-term and long-term disruptions caused by node failures and link failures on the domestic Indian airport network (IAN). The authors reported that the IAN is a small-world network and then proposed a set of graph analysis techniques to identify the resilience of IAN. By simulating a set of given attack scenarios, it was shown that IAN is robust under random failures but rather susceptible to targeted attacks.

Ribeiro et al., 2018 [16] Studied the resilience of the US airport network under three different attack scenarios: random failures together with degree-based and betwenness-based attacks. Several topological properties were compared for the networks induced by these attacks.

Baruah et al., 2018 [17] Adopted a complex network approach to analyze the robustness of three individual airlines of India, i.e., the networks of Indigo, Air India, and Jet Airways. The authors performed various attacks, distinguishing random failures and targeted attacks on these separate networks. Targeted attacks were based on the computation of node importance, which was based on the degree and betweenness centrality of nodes.

Bharali et al., 2018 [18] Used a complex network tool to study the robustness of the airport network of India. The network was found to reveal small-world properties with an average path length of 2.262 and a clustering coefficient of 0.605 and also showed disassortative mixing patterns for nodes. The authors reported that the network was less robust to node removal. Further experiments were performed on targeted attacks to the network.

Alamsyah et al., 2019 [19] Simulated disruptions in two different scenarios, comparing random failures and hub-based attacks, with a case study on the Indonesian airport network (103 nodes and 605 edges). The chosen robustness measures were the size of the giant components and the survived links. Hub nodes were identified by sorting the nodes in decreasing order of their betweenness. The authors found that the network formed a scale-free network with heavy-tailed degree distribution. The network was robust under random failures but extremely fragile under hub-based attacks. Under the latter strategy, the network was split into components of less than $50 \%$, when attacking about ten nodes.

Chen et al., 2019 [20] Analyzed the robustness of the Chinese airport network (229 airports and 2933 links) under random failures and targeted attacks. It was not clearly stated how the attacks were targeted (called planned attacks); the authors likely used decreasing degree. The results of the Chinese network were compared to some classes of random networks (WS and BA), concluding that BA was the most robust network type. Finally, the authors recommended that the hub airports in the Chinese network need to be protected further. 

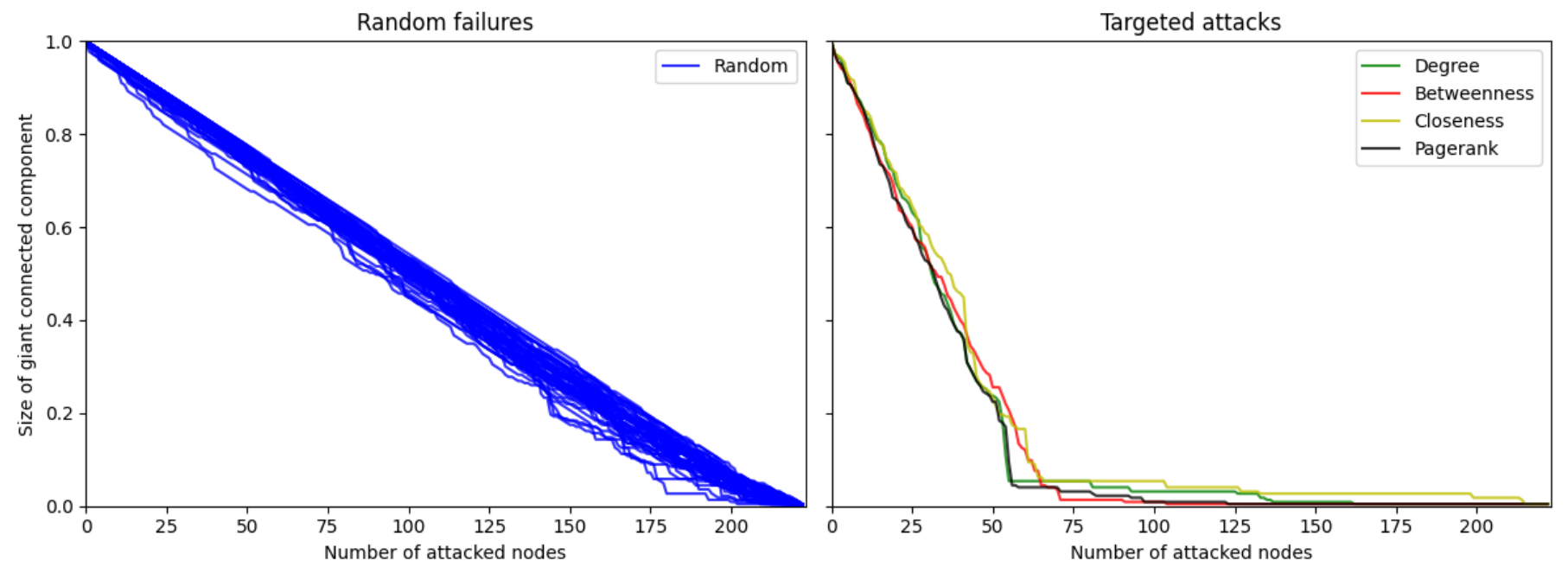

Figure 2. Example of random versus targeted attacks in the Chinese airport network.

Overall, it is intuitively expected that targeted attacks are more harmful than random failures, since the notion of being a targeted attack implies that nodes are chosen in an informed way. In fact, it is difficult to imagine a network topology for which random failures have similar harmful effects as targeted attacks. On the other hand, one could argue that attacks following the increasing degree of nodes in the network are possibly less harmful than random failures. Yet, it is doubted whether identifying such a best-case attack (in terms of the network being resilient) is a worthwhile research undertaking. Nevertheless, the finding that targeted attacks are significantly more harmful than random ones has raised tremendous interest in the literature, even in recent years.

\subsection{Critical Node Identification}

Contrary to the general observation of targeted attacks being more effective than random failures, several studies investigated the actual differences between targeted attacks and how to improve the effectiveness of attacks toward the network. Identifying vital nodes is important across many domains with large potential impacts on our society. While it is clear that major airports (in terms of passenger throughput) play important roles, it is often the case that smaller airports, which have less direct connections but are placed at topologically-important locations, play a significant role for resilience [10]. Accordingly, in order to ensure sustainable mobility and avoid high economic losses, we need to better understand nodes in the network that are of outstanding importance.

In network science; there is a plethora of methods to identify the importance of a node. One of the most commonly used methods is to assign a value to the importance of each node, based on some centrality metric. Such metrics assign a centrality value (usually normalized between zero and one) to each node, with a higher value indicating a higher level of importance. In general, one can distinguish local and global node centralities, where the former consider parts of the network for each node's importance and the latter consider information from the full network. An example for a local metric is degree, which simply counts the number of direct neighbors of each node.

Betweeness, which measures the number of shortest paths a node appears on, is a global node centrality. There are several other ways to identify node importance, e.g., by spreading processes or the explicit formulation of a network dismantling problem. In Table 2, we review studies discussing the node importance on different subsystems. Many studies use existing centralities and compare their effects on the network at hand, while a few other studies propose specific algorithms to solve the dismantling problem. 
Table 2. Critical node identification.

\begin{tabular}{|c|c|}
\hline Study & Major Finding \\
\hline Wuellner et al., 2010 [21] & $\begin{array}{l}\text { Analyzed the US airport network and compared different targeted attacks. Moreover, a rewiring method for } \\
\text { increasing the resilience under maintaining the the total number of flights and gate requirements was proposed. }\end{array}$ \\
\hline Wang et al., 2011 [22] & $\begin{array}{l}\text { Explored the critical nodes in a subset of the Chinese air transportation city network (144 nodes and } 1018 \text { links) } \\
\text { based on node centrality measures, which were found to be highly correlated with socio-economic indicators. }\end{array}$ \\
\hline Mirzasoleiman et al., 2011 [23] & $\begin{array}{l}\text { Investigated failure cascades in the weighted US airport network ( } 500 \text { nodes and } 2980 \text { links).The network } \\
\text { weighted based on the product of betweenness centrality of the end nodes led to the highest robustness. }\end{array}$ \\
\hline Wilkinson et al., 2012 [24] & $\begin{array}{l}\text { Investigated the vulnerability of the European airport network to spatial hazards, arguing that spatially coherent } \\
\text { phenomena were much more damaging than uniformly random ones. }\end{array}$ \\
\hline Conti et al., 2013 [25] & $\begin{array}{l}\text { Disruptions to the US airport network ( } 2610 \text { nodes and } 64,204 \text { edges) based on centralities were analyzed, } \\
\text { including PageRank, Hubs/Authorities, closeness, and betweenness. }\end{array}$ \\
\hline Kim et al., 2013 [26] & $\begin{array}{l}\text { Explored the robustness of network under attacker and defender interactions, with a use case on the US airport } \\
\text { network ( } 1574 \text { nodes and } 28,236 \text { links). }\end{array}$ \\
\hline Marzuoli et al., 2014 [27] & $\begin{array}{l}\text { Studied the resilience of the US airport network under different attack strategies (degree, distance strength, and } \\
\text { outreach) and discussed inducing potential vulnerability of the air transportation system. }\end{array}$ \\
\hline Wandelt et al., 2015 [28] & $\begin{array}{l}\text { Proposed a novel attack computation strategy for air transportation networks, based on a Monte-Carlo tree } \\
\text { search. }\end{array}$ \\
\hline Cunha et al., 2015 [29] & $\begin{array}{l}\text { Developed a module-based attack method, based on topological communities, which was evaluated on the US } \\
\text { airport network ( } 1574 \text { nodes and } 17,215 \text { links). }\end{array}$ \\
\hline Clusella et al., 2016 [30] & Explosive percolation was investigated on a subset of the global airline network ( 3151 nodes and 27,158 links). \\
\hline Wei et al., 2016 [31] & $\begin{array}{l}\text { Used spectral clustering to identify the critical airports in the Chinese airport network, leading to six distinct } \\
\text { categories of criticality. }\end{array}$ \\
\hline Jos et al., 2017 [32] & $\begin{array}{l}\text { Analyzed the robustness of the worldwide airport network, comparing the effects of network metrics, meta- } \\
\text { heuristics, and some customized heuristics. }\end{array}$ \\
\hline Sun et al., 2017 [33] & $\begin{array}{l}\text { Examined the resilience of the worldwide airport network ( } 3885 \text { nodes and } 228,080 \text { links) under a wide range of } \\
\text { targeted attacks, using difference attacking strategies and resilience measures. }\end{array}$ \\
\hline Clark et al., 2018 [34] & $\begin{array}{l}\text { Node properties in the US air transportation network ( } 1261 \text { nodes) were found to have central roles for robustness } \\
\text { and recovery. }\end{array}$ \\
\hline Faramondi et al., 2018 [35] & $\begin{array}{l}\text { They were concerned with the identification of critical nodes using a integer linear programming model. Experi- } \\
\text { ments on the US airport network ( } 332 \text { nodes and } 2126 \text { links) showed the effectiveness of the heuristic. }\end{array}$ \\
\hline Wandelt et al., 2018 [36] & $\begin{array}{l}\text { Discussed the usage of degree centrality for estimating network robustness in an air transportation network, } \\
\text { which led to significant overestimations. }\end{array}$ \\
\hline Clemente et al., 2019 [37] & $\begin{array}{l}\text { The effective resistance centrality, as a relative drop of the Kirchhoff index, was assessed on the US air transportation } \\
\text { network (1149 nodes and 12,145 edges). }\end{array}$ \\
\hline Wen et al., 2018 [38] & $\begin{array}{l}\text { Proposed a node importance ranking based on so-called no-return nodes. Results on the Chinese airport network } \\
\text { (199 nodes) and the US airport network ( } 332 \text { nodes and } 2126 \text { links) were reported. }\end{array}$ \\
\hline Abid et al., 2019 [39] & $\begin{array}{l}\text { Critical nodes in the Pakistan airport network ( } 44 \text { airports) were identified, mainly based on degree, closeness, } \\
\text { and betweenness. }\end{array}$ \\
\hline Wong et al., 2020 [40] & $\begin{array}{l}\text { Used data-driven methods to analyze the resilience of individual US airline networks; it was shown that } \\
\text { simultaneously considering multiple approaches led to a more comprehensive understanding of the robustness. }\end{array}$ \\
\hline Sun et al., 2020 [41] & $\begin{array}{l}\text { Identified the critical nodes in the air transportation city network ( } 3511 \text { cities), where nodes were multiple airport } \\
\text { regions and links represented flights between cities. }\end{array}$ \\
\hline Chen et al., 2020 [42] & $\begin{array}{l}\text { The network robustness evolution of the Chinese air transportation city network from } 1975 \text { to } 2017 \text { (up to } 211 \\
\text { nodes and } 2061 \text { links) was analyzed. }\end{array}$ \\
\hline
\end{tabular}

\subsection{Link Failures in Airline Networks}

The previous sections were concerned with the robustness of airport networks against node failures or node attacks. The response of air transportation networks to node attacking strategies is rather well-investigated. Another element of networks are links, connecting two nodes; considerably fewer studies have analyzed link-based disruptions. Links are similarly important to a sustainable aviation future, as are nodes. The only difference is that, for the air transportation system, it is, in general, easier to connect two airports via a link, than it is to build up a new airport. Nevertheless, highly-competitive slot auctions at major airports and the necessity to have departure slots and matching landing slots make 
it often difficult to freely add links to the system. Therefore, the importance of links should not be neglected.

Figure 3 provides an example for link importance on the Chinese airport network, comparing the importance by the number of flights (left) to the importance by the betweenness centrality of the links (right). Choosing the right measure is of high importance for assessing the roles of links in a network. On a side note, causes for link failures could mainly be seen in weather-induced phenomena, which prevent aircraft to efficiently connect pairs of airports. Table 3 gives an overview on the studies on link failures in airport networks. These studies rely, for instance, on topological measures [43], the concept of bridges [44], algebraic connectivity [45], and percolation [46].
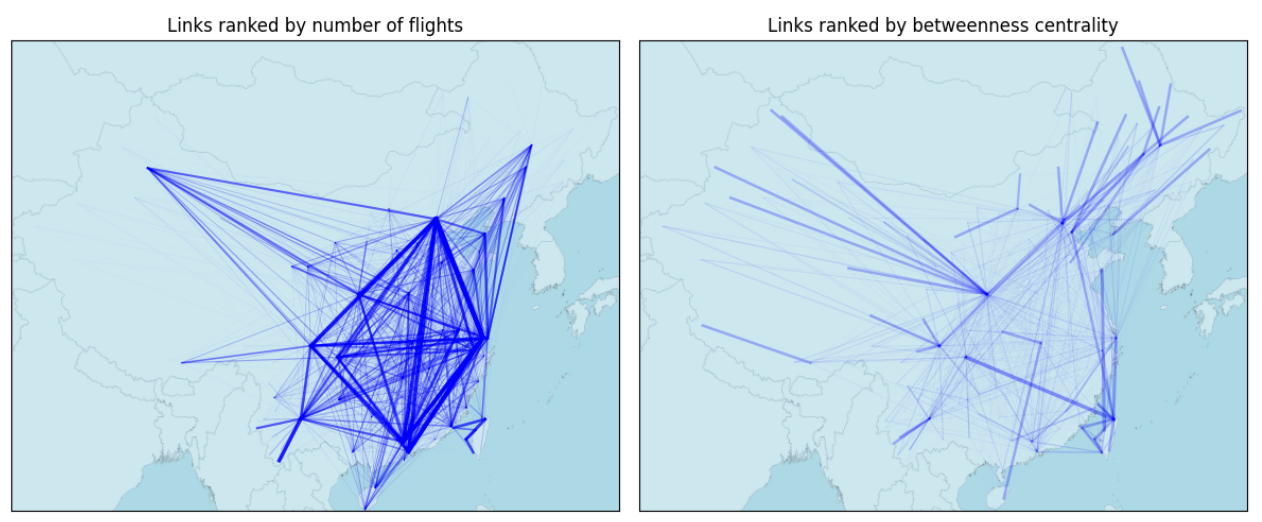

Figure 3. Example of important links in the Chinese airport network.

Table 3. Link failures in airline networks.

\begin{tabular}{ll}
\hline Study & Major Finding \\
\hline Wei et al., 2014 [45] & $\begin{array}{l}\text { Used algebraic connectivity as a robustness measure and discussed an optimization problem re- } \\
\text { garding flight route addition and deletion; a Modified Greedy Pertubation algorithm was proposed } \\
\text { for obtaining local optima. The airline network of Virgin America was used for computational } \\
\text { experiments. }\end{array}$ \\
\hline Kitsak et al., 2018 [46] & $\begin{array}{l}\text { Analyzed the stability of the giant component; which measures the overlap of unaffected nodes } \\
\text { under different link removal strategies. Experiments on the US airport network (1574 nodes and } \\
\text { 28,236 links) showed that network robustness and stability were independent phenomena. }\end{array}$ \\
\hline Kashyap et al., 2019 [43] & $\begin{array}{l}\text { Investigated the link deletion problem on the worldwide airport network, comparing random } \\
\text { link losses and three targeted strategies, based on edge betweenness, edge degree, and a combina- } \\
\text { tion thereof. }\end{array}$ \\
\hline Shiyan et al., 2020 [44] & $\begin{array}{l}\text { Studied the percolation transition in temporal networks, with the US airport network (269 airports } \\
\text { and 1896 links) as a case study, identifying critical links bridging different airport clusters. }\end{array}$ \\
\hline
\end{tabular}

\subsection{Improvement of Airline Network Robustness}

While Section 2.3 discusses how the failure of links affects the network, several recent studies addressed the inverse question: How can the robustness of the network be improved by adding links? It should be noted that adding nodes to the network does not contribute to the increase of robustness, and therefore only link additions are studied in the literature. Essentially, the goal of most studies is to identify airport pairs that are not directly connected and simulate/predict how the addition of a link affects the overall robustness of the network.

This task has a tremendous direct importance for the sustainability of the aviation system in the long run, aiming to not only incorporate enhancements that increase passenger connectivity but also consider alternative routes under failures and attacks. A system that is more resilient to such disruption will be beneficial for the whole of society; informed approaches of how to improve the robustness are of tremendous importance. 
We review these studies in Table 4. The literature should be distinguished into two types: performing recovery and rewiring strategies. The studies concerned with recovery usually address the problem of a disrupted network and how to regain functionality. The studies concerned with rewiring aim to increase the robustness before the actual event, by adding new links. Some of these studies enforce the existence of constraints during rewiring, such as the preservation of the degree distribution, which means that the topology of the underlying network does not change significantly.

Table 4. Improvement of airline network robustness.

\begin{tabular}{|c|c|}
\hline Study & Major Finding \\
\hline Hao et al., 2011 [47] & $\begin{array}{l}\text { Developed a genetic algorithm to optimize airline route networks in terms of the network properties, with the } \\
\text { ultimate goal to increase the reliability of airspace systems. }\end{array}$ \\
\hline Kim et al., 2013 [26] & $\begin{array}{l}\text { Explored the robustness of a network under attacker and defender interactions, with a use case on the US airport } \\
\text { network ( } 1574 \text { nodes and } 28,236 \text { links). We found that the best attack strategy was based on the betweenness and } \\
\text { the best defense strategy in a network was balanced replenishment. }\end{array}$ \\
\hline Wei et al., 2013 [48] & $\begin{array}{l}\text { Took the algebraic connectivity as a robustness measure and proposed to maximize the robustness by adding edges } \\
\text { and increasing edge weights. Experimental results were reported on a subset of the US city air transportation } \\
\text { system (100 nodes). }\end{array}$ \\
\hline Yang et al., 2014 [49] & $\begin{array}{l}\text { Proposed a method for improving the robustness of the US airport network while preserving its community } \\
\text { structure, given that the community structure is a characteristic of the network. }\end{array}$ \\
\hline Gallos et al., 2015 [50] & $\begin{array}{l}\text { Proposed a self-healing strategy for networks, where, after incurring damage, nodes decide independently on } \\
\text { whether to create a new link based on the fraction of lost neighbors. In computational experiments, it was } \\
\text { shown that for the US airport network ( } 332 \text { nodes), the self-healing algorithm rejoined almost } 90 \% \text { of the } \\
\text { attack-surviving airports. }\end{array}$ \\
\hline Dunn et al., 2016 [51] & $\begin{array}{l}\text { Developed two strategies to increase the resilience of an air transportation network. One strategy adaptively } \\
\text { modified the topology under airport closure and the other strategy performed permanent hazard mitigation. The } \\
\text { European air traffic network ( } 525 \text { airports and } 3886 \text { links) was used to show the effectiveness and efficiency of the } \\
\text { developed strategies. }\end{array}$ \\
\hline Hayasaka et al., 2016 [52] & $\begin{array}{l}\text { Investigated the process of explosive percolation on the US airline network (1060 nodes). Choosing specific orders } \\
\text { of edge addition had significant effects on the network robustness. }\end{array}$ \\
\hline Gunasekara et al., 2018 [53] & $\begin{array}{l}\text { Proposed a method to improve the robustness of a network with respect to multiple, conflicting objectives. } \\
\text { Experiments on the US airport network ( } 1574 \text { nodes and } 28,236 \text { links) revealed that the strategy was effective under } \\
\text { budget constraints. }\end{array}$ \\
\hline Bai et al., 2018 [54] & $\begin{array}{l}\text { Developed a smart rewiring technique that aimed to increase the robustness of the network. The algorithm } \\
\text { preserved the degree of each node, and swapped link pairs based on a hill-climbing algorithm. It was evaluated on } \\
\text { the US airport network ( } 235 \text { nodes and } 1297 \text { links). The results showed that smart rewiring led to better robustness } \\
\text { compared to random rewiring. The authors also reported that most of the small circles in the network connected } \\
\text { with the minority of large circles-leading to the observation that, once a high degree node was removed, the } \\
\text { low-degree nodes became isolated quickly. }\end{array}$ \\
\hline Clark et al., 2018 [34] & $\begin{array}{l}\text { Found that node properties in the US air transportation network ( } 1261 \text { nodes) had central roles in the process of } \\
\text { robustness. The study analyzed not only the effect of disruptions but also the effect of recovery strategies. }\end{array}$ \\
\hline Yang et al., 2019 [55] & $\begin{array}{l}\text { Aimed to design robust airport networks, while minimizing the total effective resistance using a mixed integer } \\
\text { nonlinear program. The authors proposed exact methods and a greedy heuristic, which were evaluated on different } \\
\text { subsets of the worldwide airport network. }\end{array}$ \\
\hline Zhou et al., 2020 [56] & $\begin{array}{l}\text { Introduced several restoration prioritization strategies (random, degree-based, short-time-first, and high-load-first), } \\
\text { which help to recover a network from a cascading failure. the Experiments were performed on the US airport } \\
\text { network ( } 500 \text { nodes and } 2980 \text { links). }\end{array}$ \\
\hline Wang et al., 2020 [57] & $\begin{array}{l}\text { Discussed the resilience of the air traffic control sector network of China. Furthermore, a set of recovery strategies } \\
\text { were presented and compared; betweenness was found to have the greatest importance of resilience. }\end{array}$ \\
\hline
\end{tabular}

\subsection{System Properties}

Several studies have analyzed the properties of the air transportation system and how these properties influence the resilience of the network or change throughout a disruption. Contrary to the literature in Section 2.1, these studies reviewed below had a stronger focus on disruption analysis of the system using comprehensive tools developed for network science. These studies do not have a direct impact on the sustainability of aviation but can help to understand the patterns and dynamics a system undergoes throughout a disruption. Deeper knowledge on these system evolutions helps to build better simulations 
and tools for the early detection of significant network changes. Table 5 gives an overview on these studies.

Table 5. System properties.

\begin{tabular}{|c|c|}
\hline Study & Major Finding \\
\hline Chi et al., 2004 [11] & $\begin{array}{l}\text { Studied the US airport network and investigated how topological properties (such as the degree, } \\
\text { clustering coefficient, and diameter) change under disruptions, once specific airports are removed. } \\
\text { Finally, changes to the degree distribution were reported as well. }\end{array}$ \\
\hline Bagler et al., 2008 [58] & $\begin{array}{l}\text { Performed a preliminary analysis on the airport network of India ( } 79 \text { nodes and } 449 \text { edges). The } \\
\text { paper recommended to use betweenness centrality for the identification of important airports, which } \\
\text { should be extended/protected in the future. }\end{array}$ \\
\hline Bagler et al., 2008 [59] & $\begin{array}{l}\text { Analyzed the airport network of India ( } 79 \text { nodes and } 442 \text { links). The authors reported that-contrary } \\
\text { to the global airport network-the India airport network has disassortative mixing patterns offset by } \\
\text { traffic dynamics. Furthermore, unweighted and weighted variants were compared. }\end{array}$ \\
\hline Verma et al., 2014 [60] & $\begin{array}{l}\text { Investigated the worldwide airport network ( } 3237 \text { nodes and } 18,125 \text { links), which was found to } \\
\text { consist of a highly-resilient core of about } 2.3 \% \text { of the nodes and an extremely fragile star-like periphery. } \\
\text { Once the core was removed, } 90 \% \text { of all airports were still connected. }\end{array}$ \\
\hline Wang et al., 2016 [61] & $\begin{array}{l}\text { Discussed the effects of abnormal cascading failure spreading in the US airport network ( } 500 \text { nodes } \\
\text { and } 5960 \text { links), where the increase of node capacities does not lead to a monotonous increase of the } \\
\text { network robustness. }\end{array}$ \\
\hline Voltes et al., 2017 [62] & $\begin{array}{l}\text { Performed computational experiments on the European airport network from the perspective of } \\
\text { passenger delays. The most critical airports were identified according to their aggregate delays. }\end{array}$ \\
\hline Kim et al., 2019 [63] & $\begin{array}{l}\text { Analyzed the robustness of the Northeast Asian air route network, finding that the network was more } \\
\text { vulnerable to targeted attacks rather than to random failures. Moreover, they found that rerouting } \\
\text { improved the flight operability significantly; and the identification of critical nodes provided key } \\
\text { insights for regional coordination against hazards and risks. }\end{array}$ \\
\hline Cai et al., 2020 [64] & $\begin{array}{l}\text { Reported the so-called robustness paradox in air traffic networks where the removal of links from } \\
\text { the network improves the robustness. The observation should be take with care, since under the } \\
\text { removal of links from the network, the revised robustness measure considers less (connected) nodes, } \\
\text { and therefore the improvement in robustness is explained. }\end{array}$ \\
\hline
\end{tabular}

\subsection{Networks of Networks}

The aforementioned studies typically analyzed the air transportation system as single networks. In reality, however, the air transportation system consists of multiple, interacting networks. For instance, each airline on its own induces an airport network. In Table 6, we review studies that emphasize the multi-layer nature of the air transportation system.

Table 6. Networks of networks.

\begin{tabular}{ll}
\hline Study & Major Finding \\
\hline Cardillo et al., 2013 [6] & $\begin{array}{l}\text { Investigated the multi-layer nature of the European air transportation network, by breaking individ- } \\
\text { ual airlines into separate networks. The authors analyzed the resilience of the resulting multiplex } \\
\text { system against random flight failures, under the consideration of passenger rescheduling. They } \\
\text { found that the multiplexity had strong effects on the robustness of the overall system. }\end{array}$ \\
\hline Ouyang et al., 2015 [65] & $\begin{array}{l}\text { Investigated the robustness of the Chinese airport network in the presence of a complementary rail } \\
\text { transportation network, highlighting the positive effects networks can have on each other. }\end{array}$ \\
\hline Radicchi et al., 2015 [66] & $\begin{array}{l}\text { Analyzed the interaction between different airlines during percolation in multi-layered networks } \\
\text { with a use case on the US airport network and leading to the identification of high-quality edges that } \\
\text { avoid truly catastrophic changes in the system's connectedness. }\end{array}$ \\
\hline Hackett et al., 2016 [67] & $\begin{array}{l}\text { Studied the concept of bond percolation on multiplex networks. Multiple percolation phase transi- } \\
\text { tions were identified in the European air transportation network (37 layers over 450 nodes) inter- } \\
\text { twined with the London rail network. }\end{array}$ \\
\hline Sun et al., 2018 [68] & $\begin{array}{l}\text { Investigated the robustness of more than 200 distinct airline networks and how their complementary } \\
\text { strength could compensate for individual disruptions. Experiments were performed under different } \\
\text { passenger rerouting considerations. }\end{array}$ \\
\hline
\end{tabular}




\subsection{Robustness Measurement and Simulation}

The group of studies reviewed in this subsection concerns the measurement process of robustness for a given network representation, except from the size of the giant component. The size of the giant components-and its evolution throughout attack evolution, is frequently used in the literature. However, this comes with a set of limitations, which are addressed in the studies discussed in Table 7 . These aim to propose specific frameworks for identifying the robustness of an airport network. The exploited techniques are rather distinct conceptually, e.g., using shock propagation [69], fuzzy soft sets [70], adaptive capacity [71], rerouting-based approaches [72]. Most of these are evaluated on the US airport network — due to freely available data—and the Chinese airport network.

Table 7. Robustness measurement and simulation.

\begin{tabular}{|c|c|}
\hline Study & Major Finding \\
\hline Li et al., 2015 [70] & $\begin{array}{l}\text { Used fuzzy soft sets to analyze the robustness of the US airport network and the Chinese airport } \\
\text { network, taking into account functional features induced by the traffic flow distribution. }\end{array}$ \\
\hline Pien et al., 2015 [73] & $\begin{array}{l}\text { Studied the European airport network from a topological and operation analysis by applying a } \\
\text { flow-maximization model and introducing the relative area index. }\end{array}$ \\
\hline Bianconi et al., 2016 [74] & $\begin{array}{l}\text { Proposed an exact mathematical framework for the site-percolation in multiplex networks. The goal } \\
\text { was to successfully predict the percolation diagrams of networks under exploitation of the locally } \\
\text { treelike property. The approach was evaluated on three US airline network pairs; and it was shown } \\
\text { that the framework accurately provided better predictions than the state of the art. }\end{array}$ \\
\hline Yoo et al., 2016 [71] & $\begin{array}{l}\text { Used the US airport network ( } 296 \text { nodes and } 9273 \text { links) to explore the notion of adaptive capacity, } \\
\text { which was used to measure the resilience of the network. Computational experiments revealed the } \\
\text { vulnerable and resilient regions in the system. }\end{array}$ \\
\hline Cerqueti et al., 2019 [69] & $\begin{array}{l}\text { Investigated the robustness of two subsystems of the weighted US airport network: airports in } \\
\text { Illinois ( } 12 \text { nodes and } 51 \text { links) and New York ( } 21 \text { nodes and } 89 \text { links). The authors proposed a novel } \\
\text { resilience measure based on shock propagation along the patterns of connections among nodes. They } \\
\text { argued that a complete disappearance of nodes from the network is unlikely but rather considered a } \\
\text { degradation in system performance, as, for instance, induced by partially adverse weather conditions. } \\
\text { Intuitively, shocks occurred at individual nodes first and then propagated through adjacent nodes; } \\
\text { with the effect magnitude changing as a function of the shock distance. }\end{array}$ \\
\hline Wang et al., 2019 [75] & $\begin{array}{l}\text { Proposed a model to measure the resilience of airport networks by considering the structural and } \\
\text { dynamical aspects. A case study on China's airport network ( } 251 \text { nodes) was used to show the } \\
\text { model's adequateness. }\end{array}$ \\
\hline Zhou et al., 2019 [76] & $\begin{array}{l}\text { Proposed a network efficiency metric for weighted airport networks, and evaluated the metric on } \\
\text { eight domestic airport networks; critical airports were identified, and the impact of link weights was } \\
\text { discussed. }\end{array}$ \\
\hline Yassien et al., 2020 [72] & $\begin{array}{l}\text { Based on integrating travel time and flight frequencies, developed best-route and link-weight } \\
\text { approaches to measure the robustness of the Canadian airport network ( } 47 \text { nodes and } 123 \text { links). }\end{array}$ \\
\hline Lesko et al., 2020 [77] & $\begin{array}{l}\text { Analyzed the robustness of a subset of the US airport network as induced by United Airlines by } \\
\text { using the percolation flow threshold on blocking nodes. Results were reported for the Jet Airways } \\
\text { network over India. }\end{array}$ \\
\hline
\end{tabular}

\subsection{Others}

A few other studies in the literature do not fit any of the earlier categories. These studies are reviewed in Table 8. 
Table 8. Other studies on air transportation robustness.

\begin{tabular}{ll}
\hline Study & Major Finding \\
\hline Lacasa et al., 2009 [78] & $\begin{array}{l}\text { Investigated the jamming transition over the European airport network (585 airports and 11,170 } \\
\text { flights) regarding the dynamics of aircraft diffusion. The transition between distinct regimes was } \\
\text { found to be critical. }\end{array}$ \\
\hline Wandelt et al., 2015 [79] & $\begin{array}{l}\text { Studied the air transportation country network (222 nodes and } 4620 \text { links) and identified critical } \\
\text { countries from the topological and functional perspective. Experiments were performed along the } \\
\text { temporal evolution of 12 years. }\end{array}$ \\
\hline Sun et al., 2017 [80] & $\begin{array}{l}\text { Studied the international air transportation country network (223 nodes and 5119 links), where nodes } \\
\text { are countries and links represent flights between countries. The distinct role of countries in the } \\
\text { system is analyzed and explained. }\end{array}$ \\
\hline Zanin et al., 2018 [81] & $\begin{array}{l}\text { Discussed how the use of non-normalized measures over air transportation networks leads to } \\
\text { misleading observations. }\end{array}$ \\
\hline Wang et al., 2019 [82] & $\begin{array}{l}\text { Revealed and discussed the existence of so-called alternative airport pairs, where when two airports } \\
\text { form a pair, one airport can take over the operation of another airport under disruption. Experiments } \\
\text { were performed on the airport networks of India and US. }\end{array}$ \\
\hline Sano et al., 2020 [83] & $\begin{array}{l}\text { Analyzed the US airport network (346 nodes and 5186 flights) as a temporal network, lifting several } \\
\text { centralities from static networks to temporal networks. In addition, the notion of efficiency was } \\
\text { compared to measures based on the giant component. }\end{array}$ \\
\hline Siozos et al., 2020 [84] & $\begin{array}{l}\text { Performed a study on the temporal evolution of the US airport network, with a focus on the tolerance } \\
\text { toward disruptions. Distinct years were treated as individual snapshots. }\end{array}$ \\
\hline
\end{tabular}

\section{Air Transportation Robustness and Aviation Sustainability}

Since the emergence of aviation, a major focus of all stakeholders has been on the safety of operations, with the ultimate goal to prevent damage and injury to humans and infrastructure. This goal has been mainly achieved through the elimination or mitigation of potential hazards. While passengers are highly concerned about safety, airlines and airports have been under tremendous pressure to be profitable. Given the extremely high capital cost of airlines and airports, these entities often rely on external funding and need to satisfy their venture capitalists' desire to increase profits. It becomes increasingly clear that the goal of safe aviation and highly profitable aviation are working in opposite directions; as robustness often requires redundancy, which in turn requires additional costs.

In this work, we reviewed the existing literature on complex network-based robustness of air transportation systems. These studies usually describe a part of the aviation system as a network as well as the analyzed topological properties and derive estimations on the network robustness or resilience as well as strategies for improving the network into becoming more robust. Many studies report the existence of phase transitions in the percolation process, which means that there is a sudden transition from the system working toward the system breaking down.

Identifying the properties and conditions of the phase transitions is the the heart of network robustness analysis and is critical for better understanding our aviation system. For instance, several domestic air transportation networks were reported to break down upon the failure of a few selected airports. This effect is often due to the network structure being designed for efficient hub-and-spoke operations. Notably, efficiency here should be understood from an operator's perspective, i.e., taking the view of airlines. For passengers, these hub-and-spoke connections are often rather inconvenient, since they require multiple stopovers, particularly on thin markets with fewer demands.

Recently, aviation stakeholders have acknowledged these passenger preferences, and have aimed to change their network structure toward more passenger-friendly operations, by, e.g., retiring wide body aircraft and rather focusing on smaller aircraft, which are then used to satisfy thin markets; notably, this trend has been pushed by the existence of low-cost carriers, whose business model is simply to fill this gap left by the major traditional carriers. These ongoing changes to the network structure induce changes to the robustness and 
resilience of the aviation system. It is of tremendous importance to better understand the inherent dynamics of future network structure to reach the goal of sustainable aviation.

In addition to the direct effect on the network's robustness, there exist a few other sustainability-related issues of importance. In order to provide an efficient and resilient aviation system, megacities increasingly makes use of multiple airport regions, where several airports satisfy the high demand of the population; the airport choice behavior inside such large agglomerations is not well understood, as it depends on complex interactions of land-side accessibility, air-side accessibility, operating airlines, and passenger-specific preferences.

To build a sustainable system, we need to better understand the airport choice behavior in megacities as induced by how the complex network structure together with its robustness. Recently, a highly important challenge for sustainable aviation is how to reduce fuel consumption and noise pollution to reach the goal of greener aviation. Network robustness is indirectly related to this issue since the underlying route structure and aircraft parameters largely determine the possible space of aircraft trajectories and overflight regions. For instance, the availability of free-flight trajectories enables significant reductions in aircraft emissions, while giving up on an explicit network structure.

Finally, we would like to emphasize that the ongoing COVID-19 pandemic provides ample opportunity to rethink mobility and aviation in particular. When redesigning the underlying networks for sustainable aviation, one should not neglect the inherent challenges due to the network robustness. This pandemic can be considered a critical phase yielding the chance to increase the investment into research and engineering, identifying and implementing new forms of sustainable aviation [85,86]. A development into a direction that is beneficial for society should be geared and supported by governments, for instance by providing state incentives and goal-oriented funding and making collaborative recommendations and decisions at larger scales. In doing so, one must find a balance between the economic requirements, the environmental priorities concerning the issues of pollution, and a robust operation of the aviation system, leading toward sustainable aviation.

\section{Discussion of Future Research Directions}

The paper provides a comprehensive review on the literature for estimating and improving air transportation robustness. Within the last 15 years, due to the emergence of network science tools to discover hidden patterns in complex systems, a wide range of studies have been published, covering various topics of system robustness, including node/link importance, system evolution, and recovery from failures. Overall, more than 100 studies were hand-collected and analyzed for this review. We can conclude that some of these topics are much better explored and understood than others.

In the following, we provide a set of future research recommendations, which we hope will further contribute to the literature. The below-raised observations and challenges, which were developed through the analysis of the reviewed literature, yield a research agenda for future work on air transportation robustness. Notably, these future research directions not only technically enhance our understanding of air transportation but also ensure the long-term, sustainable planning and operation of air transportation as a system in our increasingly connected and optimized world.

\subsection{The Role of Identifying Node Importance}

A significant number of studies on air transportation robustness are concerned with the identification of important nodes. In terms of network dismantling, betweenness has been found to be very effective when dismantling a network [87]. The betweenness of a node depends on the number of shortest paths it lies on while taking all possible node pairs as origins and destinations. Several assumptions here are problematic. First of all, not all origin-destination pairs have an equal demand in the network; connections between larger airports usually have many more flights and passengers than rural airports. 
Second, these node importance measures are based on the idea that nodes are completely removed from the system. This is a very strong assumption. Particularly, when being extended to more than a few airports. While it is true that the whole air transportation system could be fundamentally disrupted by removing the top 50 ranked nodes, it is at least questionable how realistic such a scenario is. In other words, is it possible for an attacker to obtain control over the 50 busiest airports in the world, distributed over all continents? The answer is almost certainly no. In fact, even making the top five airports inoperable takes a highly-coordinated and sophisticated attack. Moreover, the required cost for taking out individual airports is not constant [88] but depends on many factors, including the size, level of security/safety, and also the location.

Finally, all these node centralities are based on the topology of the network. This measure neglects effects that might be of critical importance for ground processes, e.g., the presence of aircraft maintenance checks at regional airports, which cannot be identified based on topological measures. A lack of aircraft maintenance checks, however, will have tremendous impacts on the system, since aircraft will simply not be allowed to fly. Accordingly, not all airports are the same; and not all airports can simply be assessed based on their topology. Finally, future work could move away from node/link importance and rather investigate subsystems, such as communities [89].

\subsection{Hub-and-Spoke vs. Point-to-Point}

Complex network-based analysis has a strong focus on the topology of the network. From an operational perspective, this means finding a transition between hub-and-spoke and point-to-point operations. Both come with known limitations. For instance, hub-andspoke networks have a few highly-connected hubs that allow for efficient transportation of passengers with fewer hops. These hubs, however, make the system highly susceptible to failures. In point-to-point networks, there are not outstandingly-connected airports, leading to a much higher resilience, but larger operation costs, since more flights need to be offered.

\subsection{Multi-Layer Interactions}

Multi-layer interactions within the system deserve much larger attention in future research. Such interactions are not only limited to multiple airlines-as has been done in some existing studies. For instance, air transportation comes at different levels of fractality [90], where different levels of granularity (airports, multiple-airport regions, cities, counties, countries) model the same system. Investigating individual layers of the system misses opportunities to reveal hidden patterns.

Air transportation is building increasing interactions with other transportation modes, in an attempt to provide a more efficient and reliable passenger experience; one prominent example being high-speed railway systems, which have strong competition and complementary effects up to distances of $1200 \mathrm{~km}$ in China [1]. Without consideration of these interactions, one neglects ample optimization potential. The development of true multilayer and multi-modal techniques, beyond a simple treatment as individual components, requires the development of novel network analysis and optimization techniques, which can be partially found in the network science community [91,92].

\subsection{Operational Patterns and Dynamics}

Complex networks are an abstraction; in fact, one of the simplest abstractions of the air transportation system-transforming all elements into nodes and links. Naturally, such an abstraction comes at the price of simplifications; some of which might over-simplify the problem at hand and lead to unrealistic observations and possibly wrong conclusions. Accordingly, we suggest that future research moves away from purely complex networkbased representations and rather includes operational patterns on these networks. For instance, neglecting the movement of aircraft on the network likely misses a tremendous potential for disruptions at specific airports, which are used as hubs for smaller airlines. 
Accordingly, there is a huge gap in the literature on the transition from oversimplified complex network models toward scalable optimization-based air transportation resilience and recovery approaches [93-96]; the latter ones usually being highly intractable in terms of computation. Examples for other air transportation domains that could be modeled as complex networks include airport self-service locations [97], network-based representations of airport duty-free shops [98], queuing/waiting times in airports [99], or the air transportation sector and its efficiency at large $[100,101]$. We believe that studies exploiting the strengths of both domains, e.g., the tractability of complex network analysis and formal goals of optimization, will be of strategic importance for further pushing research on air transportation resilience.

\subsection{Recovery from COVID-19}

It is arguable whether the current COVID-19 pandemic can be understood as a matter of resilience; the system performance was significantly reduced throughout the year 2020 [5], which raises an analogy to the resilience of networks. A natural question arising here is what the recovery of air transportation could look like. Preliminary complex network-based analysis of the system has suggested significant differences between different stakeholders and airlines, depending on the type of competitive advantage [102].

One typical question in such studies is regarding the shape of the recovery function, usually distinguishing L-shaped (longer valley of reduced function) or U-shaped (timely recovery) [103] recovery functions. From an operational analysis, it was reported that the recovery phase could take at least $2-4$ years [104], a process involving many subjective factors, e.g., the perceived threat of COVID-19 and fear [105] and induced changes in passenger behavior [106]. This leads to a large potential for future studies to further model the recovery process using multi-layer complex networks at different scales.

\subsection{Emergence of Travel Bubbles}

As a special case for pandemic-safe transportation, the concept of travel bubbles emerged throughout the year 2020, where several regions established travel arrangements, which are also referred to as 'travel bridges', 'travel corridors', or 'corona corridors' in the literature [107]. The goal is to stimulate/maintain mobility, trade, and economic recovery in specific regions, where the number of confirmed cases allows for travels inside the bubble [108]. The design of such travel bubbles is tremendously challenging, since many factors influence the decision making; leading to evidence-based, real-time decisions regarding cross-border measures for mitigation [109,110]. Notably, such travel bubbles are not a permanent, ever-lasting decision; if there is a rise confirmed cases, these travel bubbles have to be adapted [107]. Accordingly, the design and verification of resilient travel bubbles in air transportation based on complex networks is a highly-interesting direction for future work.

\subsection{Unified Datasets and Experimental Setup}

Air transportation networks can be analyzed by at least six conceptually distinct types. First, classification concerns the dimension of scale, which is related to the concept fractality [90]. At different resolutions, e.g., airport vs. metropolitan area, the network will reveal gradually distinct structures. Second, the species of the transportation should be distinguished, e.g., business vs. leisure vs. cargo transportation. Third, air transportation has highly seasonal patterns [111]. Despite their differences, each type has a generally similar complex network architecture, with deviations in the details [112].

Accordingly, experiments on air transportation networks should be performed on comparable, unified datasets. Similarly, the setups of experiments should be performed in a unified manner. This includes the step data pre-processing, in which authors often eliminate small-scale effects (e.g., origin-destination pairs with a small number of flights or passengers) and data cleansing (e.g., joining travel data with incompatible airport 
data). Finally, there is a need to devise commonly-agreed upon primitives of robustness processing, which includes the usage of normalized network measures [81].

Author Contributions: Conceptualization, X.S. and S.W.; methodology, X.S. and S.W.; software, S.W.; formal analysis, X.S. and S.W.; writing —original draft preparation, X.S.; writing—review and editing, X.S. and S.W.; visualization, S.W.; funding acquisition, X.S. and S.W. All authors have read and agreed to the published version of the manuscript.

Funding: This research was funded by National Natural Science Foundation of China grant numbers 61861136005, No. 61851110763, and No. 71731001.

Institutional Review Board Statement: Not applicable.

Informed Consent Statement: Not applicable.

Data Availability Statement: Visualizations are based on data from https:/ / www.flightradar24.com (accessed on 4 June 2021).

Conflicts of Interest: The authors declare no conflict of interest.

\section{References}

1. Sun, X.; Zhang, Y.; Wandelt, S. Air Transport versus High-Speed Rail: An Overview and Research Agenda. J. Adv. Transp. 2017, 2017, 1-18. [CrossRef]

2. Nüchter, V.; Abson, D.J.; von Wehrden, H.; Engler, J.O. The Concept of Resilience in Recent Sustainability Research. Sustainability 2021, 13, 2735. [CrossRef]

3. Brooker, P. Fear in a handful of dust: aviation and the Icelandic volcano. Significance 2010, 7, 112-115. [CrossRef]

4. Usher, M.; Brace, A. Blackout Chaos: Travelers Could Be Stranded for Christmas Because of a Major Power Failure at the World's Busiest Airport in Atlanta. 2017. Available online: https://search.informit.org/doi/abs/10.3316/tvnews.tsm201712180011 (accessed on 20 February 2021).

5. Sun, X.; Wandelt, S.; Zhang, A. How did COVID-19 impact air transportation? A first peek through the lens of complex networks. J. Air Transp. Manag. 2020, 89, 101928. [CrossRef]

6. Cardillo, A.; Zanin, M.; Gómez-Gardenes, J.; Romance, M.; del Amo, A.J.G.; Boccaletti, S. Modeling the multi-layer nature of the European Air Transport Network: Resilience and passengers re-scheduling under random failures. Eur. Phys. J. Spec. Top. 2013, 215, 23-33. [CrossRef]

7. Barabasi, A.L. Network Science. Philos. Trans. R. Soc. A Math. Phys. Eng. Sci. 2013, 371, 20120375. [CrossRef]

8. Newman, M.E. Networks-An Introduction; Oxford University Press: Oxford, UK, 2010.

9. Zanin, M.; Lillo, F. Modelling the air transport with complex networks: A short review. Eur. Phys. J. Spec. Top. 2013, 215, 5-21. [CrossRef]

10. Guimera, R.; Mossa, S.; Turtschi, A.; Amaral, L.N. The worldwide air transportation network: Anomalous centrality, community structure, and cities' global roles. Proc. Natl. Acad. Sci. USA 2005, 102, 7794-7799. [CrossRef] [PubMed]

11. Chi, L.P.; Cai, X. Structural changes caused by error and attack tolerance in US airport network. Int. J. Mod. Phys. B 2004, 18, 2394-2400. [CrossRef]

12. Hossain, M.; Alam, S.; Rees, T.; Abbass, H. Australian Airport Network Robustness Analysis: A Complex Network Approach. In Proceedings of the 36th Australasian Transport Research Forum, Brisbane, Australia, 2-4 October 2013.

13. Bing, D. Reliability analysis for aviation airline network based on complex network. J. Aerosp. Technol. Manag. 2014, 6, 193-201. [CrossRef]

14. Li, H.; Guo, X.M.; Xu, Z.; Hu, X.B. A study on the spatial vulnerability of the civil aviation network system in China. In Proceedings of the 17th International IEEE Conference on Intelligent Transportation Systems (ITSC), Qingdao, China, 24-26 September 2014; pp. 2650-2655.

15. Agrawal, S.; Agrawal, D.; Chen, C.B.; Hutchison, K.; Kumara, S. Robustness Analysis of Indian Airport Network: A Graph Analysis Approach. In IIE Annual Conference. Proceedings; Institute of Industrial and Systems Engineers (IISE): Peachtree Corners, GA, USA , 2015; p. 1524.

16. Ribeiro, M.; Pinto, S.E.; Bortolini, D.; Lenz, W.; Balthazar, J.; Tusset, A. Failure in complex network of airport. Math. Eng. Sci. Aerosp. 2018, 9, 431-437.

17. Baruah, D.; Bharali, A. Analysis of Three Major Airline Networks of India: A Complex Network Approach. In International Conference on Applied and Computational Mathematics; Springer: Berlin/Heidelberg, Germany, 2018; pp. 503-513.

18. Bharali, A.; Baruah, D. On structure and robustness of airport network of India. Res. Rev. Discret. Math. Struct. 2018, 5, 26-33.

19. Alamsyah, A.; Ramadhani, D.P. Air Transportation Network Robustness under Random and Hub-Based Disruptions. In Proceedings of the 2019 7th International Conference on Information and Communication Technology (ICoICT), Kuala Lumpur, Malaysia, 24-26 July 2019; pp. 1-6. 
20. Chen, Z.; Zhang, G.; Gao, X.; Dong, Y. Research on the Damage Resistance of Air Transportation Network based on Complex Network Theory. In Proceedings of the 2019 5th International Conference on Systems, Control and Communications, Wuhan, China, 21-23 December 2019; pp. 76-81.

21. Wuellner, D.R.; Roy, S.; D'Souza, R.M. Resilience and rewiring of the passenger airline networks in the United States. Phys. Rev. E 2010, 82, 056101. [CrossRef] [PubMed]

22. Wang, J.; Mo, H.; Wang, F.; Jin, F. Exploring the network structure and nodal centrality of China's air transport network: A complex network approach. J. Transp. Geogr. 2011, 19, 712-721. [CrossRef]

23. Mirzasoleiman, B.; Babaei, M.; Jalili, M.; Safari, M. Cascaded failures in weighted networks. Phys. Rev. E 2011, 84, 046114. [CrossRef]

24. Wilkinson, S.M.; Dunn, S.; Ma, S. The vulnerability of the European air traffic network to spatial hazards. Nat. Hazards 2012, 60, 1027-1036. [CrossRef]

25. Conti, E.; Cao, S.; Thomas, A. Disruptions in the US airport network. arXiv 2013, arXiv:1301.2223.

26. Kim, H.; Anderson, R. An Experimental Evaluation of Robustness of Networks. IEEE Syst. J. 2013, 7, 179-188. [CrossRef]

27. Marzuoli, A.; Feron, E.; Boidot, E. Resilience of the national airspace system structure: A data-driven network approach. In Proceedings of the 2014 IEEE/AIAA 33rd Digital Avionics Systems Conference (DASC), Colorado Springs, CO, USA, 5-9 October 2014; pp. 1D21-1D213. [CrossRef]

28. Wandelt, S.; Sun, X.; Cao, X. Computationally efficient attack design for robustness analysis of air transportation networks. Transp. A Transp. Sci. 2015, 11, 939-966. [CrossRef]

29. Requião da Cunha, B.; González-Avella, J.C.; Gonçalves, S. Fast Fragmentation of Networks Using Module-Based Attacks. PLoS ONE 2015, 10, 1-15. [CrossRef] [PubMed]

30. Clusella, P.; Grassberger, P.; Pérez-Reche, F.J.; Politi, A. Immunization and Targeted Destruction of Networks using Explosive Percolation. Phys. Rev. Lett. 2016, 117, 208301. [CrossRef]

31. Cong, W.; Hu, M.; Dong, B.; Wang, Y.; Feng, C. Empirical analysis of airport network and critical airports. Chin. J. Aeronaut. 2016, 29, 512-519. [CrossRef]

32. Jos, M.S.O.L.; Sallan, M. Heuristics of node selection criteria to assess robustness of world airport network. Chin. J. Aeronaut. 2017, 30, 1473-1480.

33. Sun, X.; Gollnick, V.; Wandelt, S. Robustness analysis metrics for worldwide airport network: A comprehensive study. Chin. J. Aeronaut. 2017, 30, 500-512. [CrossRef]

34. Clark, K.L.; Bhatia, U.; Kodra, E.A.; Ganguly, A.R. Resilience of the US national airspace system airport network. IEEE Trans. Intell. Transp. Syst. 2018, 19, 3785-3794. [CrossRef]

35. Faramondi, L.; Setola, R.; Panzieri, S.; Pascucci, F.; Oliva, G. Finding critical nodes in infrastructure networks. Int. J. Crit. Infrastruct. Prot. 2018, 20,3-15. [CrossRef]

36. Wandelt, S.; Sun, X. Robustness Estimation of Infrastructure Networks: On the Usage of Degree Centrality. In Proceedings of the 13th International Conference on Availability, Reliability and Security, Hamburg, Germany, 27-30 August 2018; Association for Computing Machinery: New York, NY, USA, 2018. [CrossRef]

37. Clemente, G.P.; Cornaro, A. A novel measure of edge and vertex centrality for assessing robustness in complex networks. Soft Comput. 2019, 24, 13687-13704. [CrossRef]

38. Wen, X.; Tu, C.; Wu, M. Node importance evaluation in aviation network based on "No Return" node deletion method. Phys. A Stat. Mech. Appl. 2018, 503, 546-559. [CrossRef]

39. Abid, H.; Malik, H.A.M.; Mahmood, N.; Usman, M.H.; Rziwan, K. Analysis of Airport Network in Pakistan Utilizing Complex Network Approach. Int. J. Adv. Comput. Sci. Appl. 2019, 10. [CrossRef]

40. Wong, A.; Tan, S.; Chandramouleeswaran, K.R.; Tran, H.T. Data-driven analysis of resilience in airline networks. Transp. Res. Part E Logist. Transp. Rev. 2020, 143, 102068. [CrossRef]

41. Sun, X.; Wandelt, S.; Zhang, A. Resilience of cities toward airport disruptions at global scale. Res. Transp. Bus. Manag. 2020, 34, 100452. Data analytics for international transportation management. [CrossRef]

42. Chen, Y.; Wang, J.; Jin, F. Robustness of China's air transport network from 1975 to 2017. Phys. A Stat. Mech. Appl. 2020, 539, 122876. [CrossRef]

43. Kashyap, G.; Ambika, G. Link deletion in directed complex networks. Phys. A Stat. Mech. Appl. 2019, 514, 631-643. [CrossRef]

44. Shiyan, L.; Zhenfu, L.; Zhong, J.; Daqing, L. Percolation transition in temporal airport network. Chin. J. Aeronaut. 2020, 33, 219-226.

45. Wei, P.; Chen, L.; Sun, D. Algebraic connectivity maximization of an air transportation network: The flight routes' addition/deletion problem. Transp. Res. Part E Logist. Transp. Rev. 2014, 61, 13-27. [CrossRef]

46. Kitsak, M.; Ganin, A.A.; Eisenberg, D.A.; Krapivsky, P.L.; Krioukov, D.; Alderson, D.L.; Linkov, I. Stability of a giant connected component in a complex network. Phys. Rev. E 2018, 97, 012309. [CrossRef]

47. Liu, H.; Hu, X.B.; Yang, S.; Zhang, K.; Paolo, E.D. Application of Complex Network Theory and Genetic Algorithm in Airline Route Networks. Transp. Res. Rec. 2011, 2214, 50-58. [CrossRef]

48. Wei, P.; Spiers, G.; Sun, D. Algebraic connectivity maximization for air transportation networks. IEEE Trans. Intell. Transp. Syst. 2013, 15, 685-698. 
49. Yang, Y.; Li, Z.; Chen, Y.; Zhang, X.; Wang, S. Improving the Robustness of Complex Networks with Preserving Community Structure. PLoS ONE 2014, 10, e0116551. [CrossRef] [PubMed]

50. Gallos, L.K.; Fefferman, N.H. Simple and efficient self-healing strategy for damaged complex networks. Phys. Rev. E 2015, 92, 052806. [CrossRef] [PubMed]

51. Dunn, S.; Wilkinson, S.M. Increasing the resilience of air traffic networks using a network graph theory approach. Transp. Res. Part E Logist. Transp. Rev. 2016, 90, 39-50. [CrossRef]

52. Hayasaka, S. Explosive percolation in thresholded networks. Phys. A Stat. Mech. Appl. 2016, 451, 1-9. [CrossRef]

53. Gunasekara, R.C.; Mohan, C.K.; Mehrotra, K. Multi-objective optimization to improve robustness in networks. In Multi-Objective Optimization; Springer: Berlin/Heidelberg, Germany, 2018; pp. 115-139.

54. Bai, L.; Xiao, Y.D.; Hou, L.L.; Lao, S.Y. Smart Rewiring: Improving Network Robustness Faster. Chin. Phys. Lett. 2015, $32,078901$. [CrossRef]

55. Yang, C.; Mao, J.; Qian, X.; Wei, P. Designing Robust Air Transportation Networks via Minimizing Total Effective Resistance. IEEE Trans. Intell. Transp. Syst. 2019, 20, 2353-2366. [CrossRef]

56. Zhou, J.; Coit, D.W.; Felder, F.A.; Wang, D. Resiliency-based restoration optimization for dependent network systems against cascading failures. Reliab. Eng. Syst. Saf. 2020, 207, 107383. [CrossRef]

57. Wang, X.; Miao, S.; Tang, J. Vulnerability and Resilience Analysis of the Air Traffic Control Sector Network in China. Sustainability 2020, 12, 3749. [CrossRef]

58. Bagler, G. Complex Network view of performance and risks on Airport Networks. arXiv 2008, arXiv:0805.0924.

59. Bagler, G. Analysis of the airport network of India as a complex weighted network. Phys. A Stat. Mech. Appl. 2008, 387, 2972-2980. [CrossRef]

60. Verma, T.; Araujo, N.; Herrmann, H. Revealing the structure of the world airline network. Sci. Rep. 2014, 4. [CrossRef] [PubMed]

61. Wang, J.; Sun, E.; Xu, B.; Li, P.; Ni, C. Abnormal cascading failure spreading on complex networks. Chaos Solitons Fractals 2016, 91, 695-701. [CrossRef]

62. Voltes-Dorta, A.; Rodríguez-Déniz, H.; Suau-Sanchez, P. Vulnerability of the European air transport network to major airport closures from the perspective of passenger delays: Ranking the most critical airports. Transp. Res. Part A Policy Pract. 2017, 96, 119-145. [CrossRef]

63. Kim, S.; Yoon, Y. On node criticality of the Northeast Asian air route network. J. Air Transp. Manag. 2019, 80, 101693. [CrossRef]

64. Cai, Q.; Alam, S.; Duong, V. On robustness paradox in air traffic networks. IEEE Trans. Netw. Sci. Eng. 2020, 7, 3087-3099. [CrossRef]

65. Ouyang, M.; Pan, Z.; Hong, L.; He, Y. Vulnerability analysis of complementary transportation systems with applications to railway and airline systems in China. Reliab. Eng. Syst. Saf. 2015, 142, 248-257. [CrossRef]

66. Radicchi, F. Percolation in real interdependent networks. Nat. Phys. 2015, 11, 597-602. [CrossRef]

67. Hackett, A.; Cellai, D.; Gómez, S.; Arenas, A.; Gleeson, J.P. Bond Percolation on Multiplex Networks. Phys. Rev. X 2016, 6, 021002. [CrossRef]

68. Sun, X.; Wandelt, S. Complementary strengths of airlines under network disruptions. Saf. Sci. 2018, 103, 76-87. [CrossRef]

69. Cerqueti, R.; Ferraro, G.; Iovanella, A. Measuring network resilience through connection patterns. Reliab. Eng. Syst. Saf. 2019, 188, 320-329. [CrossRef]

70. Li, S.; Xu, X. Vulnerability analysis for airport networks based on fuzzy soft sets: from the structural and functional perspective. Chin. J. Aeronaut. 2015, 28, 780-788. [CrossRef]

71. Yoo, S.; Yeo, H. Evaluation of the resilience of air transportation network with adaptive capacity. Int. J. Urban Sci. 2016, 20, 38-49. [CrossRef]

72. Yassien, Y.; Ezzeldin, M.; Mohamed, M.; El-Dakhakhni, W. Air Transportation Infrastructure Robustness Assessment for Proactive Systemic Risk Management. J. Manag. Eng. 2020, 36, 04020037. [CrossRef]

73. Pien, K.C.; Han, K.; Shang, W.; Majumdar, A.; Ochieng, W. Robustness analysis of the European air traffic network. Transp. A Transp. Sci. 2015, 11, 772-792. [CrossRef]

74. Bianconi, G.; Radicchi, F. Percolation in real multiplex networks. Phys. Rev. E 2016, 94, 060301. [CrossRef] [PubMed]

75. Wang, Y.; Zhan, J.; Xu, X.; Li, L.; Chen, P.; Hansen, M. Measuring the resilience of an airport network. Chin. J. Aeronaut. 2019, 32, 2694-2705. [CrossRef]

76. Zhou, Y.; Wang, J.; Huang, G.Q. Efficiency and robustness of weighted air transport networks. Transp. Res. Part E Logist. Transp. Rev. 2019, 122, 14-26. [CrossRef]

77. Lesko, S.; Aleshkin, A.; Zhukov, D. Reliability Analysis of the Air Transportation Network when Blocking Nodes and/or Connections Based on the Methods of Percolation Theory. IOP Conf. Ser. Mater. Sci. Eng. 2020, 714, 012016. [CrossRef]

78. Lacasa, L.; Cea, M.; Zanin, M. Jamming transition in air transportation networks. Phys. A Stat. Mech. Appl. 2009, 388, 3948-3954. [CrossRef]

79. Wandelt, S.; Sun, X. Evolution of the international air transportation country network from 2002 to 2013. Transp. Res. Part E Logist. Transp. Rev. 2015, 82, 55-78. [CrossRef]

80. Sun, X.; Wandelt, S.; Cao, X. On Node Criticality in Air Transportation Networks. Netw. Spat. Econ. 2017, 17, 737-761. [CrossRef] 
81. Zanin, M.; Sun, X.; Wandelt, S. Studying the topology of transportation systems through complex networks: Handle with care. J. Adv. Transp. 2018, 2018. [CrossRef]

82. Wang, J.; Zhou, Y.; Huang, G.Q. Alternative pair in the airport network. Transp. Res. Part A Policy Pract. 2019, 124, 408-418. [CrossRef]

83. Sano, H.H.; Berton, L. Topology and robustness analysis of temporal air transport network. In Proceedings of the 35th Annual ACM Symposium on Applied Computing, Brno, Czech Republic, 30 March-3 April 2020; pp. 1881-1884.

84. Siozos-Rousoulis, L.; Robert, D.; Verbeke, W. A study of the US domestic air transportation network: Temporal evolution of network topology and robustness from 2001 to 2016. arXiv 2020, arXiv:2005.01101.

85. Arena, M.; Aprea, C. Impact of Covid-19 Pandemic on Air Transport: Overview and Implications. Adv. Environ. Eng. Res. 2021, 2. [CrossRef]

86. Sun, X.; Wandelt, S.; Zheng, C.; Zhang, A. COVID-19 pandemic and air transportation: Successfully navigating the paper hurricane. J. Air Transp. Manag. 2021, 94, 102062. [CrossRef]

87. Wandelt, S.; Sun, X.; Feng, D.; Zanin, M.; Havlin, S. A comparative analysis of approaches to network-dismantling. Sci. Rep. 2018, 8, 1-15. [CrossRef] [PubMed]

88. Ren, X.; Gleinig, N.; Helbing, D.; Antulov-Fantulin, N. Generalized Network Dismantling. Proc. Natl. Acad. Sci. USA 2018, 116, 6554-6559. [CrossRef]

89. Wandelt, S.; Shi, X.; Sun, X. Estimation and improvement of transportation network robustness by exploiting communities. Reliab. Eng. Syst. Saf. 2021, 206, 107307. [CrossRef]

90. Sun, X.; Wandelt, S.; Zanin, M. Worldwide air transportation networks: A matter of scale and fractality? Transp. A Transp. Sci. 2017, 13, 607-630. [CrossRef]

91. Gao, J.; Buldyrev, S.V.; Havlin, S.; Stanley, H.E. Robustness of a Network of Networks. Phys. Rev. Lett. 2011, 107, 195701. [CrossRef] [PubMed]

92. Gao, J.; Li, D.; Havlin, S. From a single network to a network of networks. Natl. Sci. Rev. 2014, 1, 346-356. [CrossRef]

93. Froyland, G.; Maher, S.J.; Wu, C.L. The recoverable robust tail assignment problem. Transp. Sci. 2013, 48, 351-372. [CrossRef]

94. Maher, S.J.; Desaulniers, G.; Soumis, F. The daily tail assignment problem under operational uncertainty using look-ahead maintenance constraints. Eur. J. Oper. Res. 2018, 264, 534-547. [CrossRef]

95. Şafak, Ö.; Çavuş, Ö.; Aktürk, M.S. Multi-stage airline scheduling problem with stochastic passenger demand and non-cruise times. Transp. Res. Part B Methodol. 2018, 114, 39-67. [CrossRef]

96. Antunes, D.; Vaze, V.; Antunes, A.P. A Robust Pairing Model for Airline Crew Scheduling. Transp. Sci. 2019, 53, 1751-1771. [CrossRef]

97. Antwi, C.O.; Ren, J.; Owusu-Ansah, W.; Mensah, H.K.; Aboagye, M.O. Airport Self-Service Technologies, Passenger Self-Concept, and Behavior: An Attributional View. Sustainability 2021, 13, 3134. [CrossRef]

98. Choi, Y.J.; Park, J.W. Investigating Factors Influencing the Behavioral Intention of Online Duty-Free Shop Users. Sustainability 2020, 12, 7108. [CrossRef]

99. Kim, M.H.; Park, J.W.; Choi, Y.J. A Study on the Effects of Waiting Time for Airport Security Screening Service on Passengers' Emotional Responses and Airport Image. Sustainability 2020, 12, 10634. [CrossRef]

100. Song, M.; Jia, G.; Zhang, P. An Evaluation of Air Transport Sector Operational Efficiency in China based on a Three-Stage DEA Analysis. Sustainability 2020, 12, 4220. [CrossRef]

101. Song, K.H.; Choi, S.; Han, I.H. Competitiveness Evaluation Methodology for Aviation Industry Sustainability Using Network DEA. Sustainability 2020, 12, 10323. [CrossRef]

102. Ye, J.; Ji, P.; Barthelemy, M. Scenarios for a Post-COVID-19 World Airline Network. 2020. Available online: https://arxiv.org/ abs / 2007.02109 (accessed on 20 February 2021).

103. Gallego, I.; Font, X. Changes in air passenger demand as a result of the COVID-19 crisis: Using Big Data to inform tourism policy. J. Sustain. Tour. 2020,1-20. [CrossRef]

104. Gudmundsson, S.; Cattaneo, M.; Redondi, R. Forecasting Recovery Time in Air Transport Markets in the Presence of Large Economic Shocks: COVID-19. SSRN Electron. J. 2020. [CrossRef]

105. Lamb, T.L.; Winter, S.R.; Rice, S.; Ruskin, K.J.; Vaughn, A. Factors that predict passengers willingness to fly during and after the COVID-19 pandemic. J. Air Transp. Manag. 2020, 89, 101897. [CrossRef] [PubMed]

106. Song, K.H.; Choi, S. A Study on the Behavioral Change of Passengers on Sustainable Air Transport after COVID-19. Sustainability 2020, 12, 9207. [CrossRef]

107. Sharun, K.; Tiwari, R.; Natesan, S.; Yatoo, M.I.; Malik, Y.S.; Dhama, K. International travel during the COVID-19 pandemic: Implications and risks associated with 'travel bubbles'. J. Travel Med. 2020, 27. [CrossRef] [PubMed]

108. Dickens, B.L.; Koo, J.R.; Lim, J.T.; Sun, H.; Clapham, H.E.; Wilder-Smith, A.; Cook, A.R. Strategies at points of entry to reduce importation risk of COVID-19 cases and reopen travel. J. Travel Med. 2020, 27. [CrossRef]

109. Lee, K.; Worsnop, C.; Grépin, K.; Kamradt-Scott, A. Global coordination on cross-border travel and trade measures crucial to COVID-19 response. Lancet 2020, 395. [CrossRef]

110. Iacus, S.; Natale, F.; Santamaria, C.; Spyratos, S.; Vespe, M. Estimating and Projecting Air Passenger Traffic during the COVID-19 Coronavirus Outbreak and its Socio-Economic Impact. Saf. Sci. 2020, 129, 104791. [CrossRef] 
111. Sun, X.; Wandelt, S.; Linke, F. Temporal evolution analysis of the European air transportation system: Air navigation route network and airport network. Transp. B Transp. Dyn. 2015, 3, 153-168. [CrossRef]

112. Neal, Z. The devil is in the details: Differences in air traffic networks by scale, species, and season. Soc. Netw. 2014, 38, 63-73. [CrossRef] 